\title{
Taşkın Tehlike Alanlarının Oluşturulması: Trabzon İli Vakfıkebir İlçesi Kirazlı Deresi Örneği
}

\author{
Esra ERTÜRK ${ }^{1 *}$, Nihat KAYA ${ }^{2}$ \\ ${ }^{1}$ Devlet Su İşleri Genel Müdürlüğü, Ankara, Türkiye \\ ${ }^{2}$ Fırat Üniversitesi Mühendislik Fakültesi İnşaat Mühendisliği Bölümü, Elazığ, Türkiye \\ *1 esraerturk@dsi.gov.tr, ${ }^{2}$ nkaya @ firat.edu.tr
}

(Geliş/Received: 28/09/2018;

Kabul/Accepted: 23/05/2019)

\begin{abstract}
Öz: Akarsu yatağının su iletim kapasitesinin çeşitli sebeplerle azalması veya yatak kapasitesinden daha fazla suyun gelmesi halinde yatak dışına taşarak can ve mal kaybına sebep olan taşkın, tedbir alınması gereken önemli afetlerden biridir. Calıșma bölgesi olan Doğu Karadeniz Havzası, hem meteorolojik açıdan fazla yağış alıyor olması sebebiyle hem de topoğrafik açıdan taşkın riski taşıması açısından önemli bir örnektir. Bu çalıșmada yerleşim alanları ile tarım alanlarının Doğu Karadeniz Havzası'nın değişik dönüş aralıkları için hesaplanan taşkın tekerrür debilerine karşılık gelen su seviyeleri ve su altında kalacak yerlerin HEC-RAS 1 ve 2 Boyutlu yazılımı kullanılarak hesaplanması amaçlanmıştır. Yapılan çalışmada yerel düzeyde tehlikeler belirlenerek ilgili kurumlar tarafından taşkın yönetim planları hazırlanmaktadır. Bu kapsamda yapılan çalışma sonucu çalışılan alanda taşkın zararlarının etkilerini en aza indirmek maksadıyla mevcut ıslah tesislerinin revize edilmesi ve taşkın erken uyarı sistemlerinin kurulması gerektiği yönünde taşkını önleyici tedbirlerin alınması gerektiği belirlenmiştir.
\end{abstract}

Anahtar Kelimeler: İklim değişikliği, taşkın, modelleme, HEC-RAS.

\section{Determination of the Flood Risk Areas: Case Study - Kirazlı Creek (Trabzon - Vakfıkebir)}

Abstract: Flooding, the water transition capacity of the riverbed decreases due to various reasons or it can cause the loss of lives and properties if excessive amount of water has been observed on the riverbed, is one of the major disasters that need to be taken as a precaution. The Eastern Black Sea Basin, which is the study area, is a significant example both because of its meteorological excess rainfall and the topographically risk of flooding. Calculation of the water levels and the places that is inundated by the flood frequency rates of the settlements and agricultural areas for the different turn intervals of the Eastern Black Sea Basin by using the HEC-RAS 1 and 2 dimensional software is aimed in this study. Dangers are determined at local level and flood management plans are prepared by related institutions. In order to minimize the effects of flood damages in the study area, it has been determined that the existing flood control facilities should be revised and flood early warning systems should be installed.

Keywords: Climate change, flood, modelling, HEC-RAS.

\section{Giriş}

Taşkın; bir akarsuyun çeşitli sebeplerle yatağından taşarak, çevresindeki arazilere, yerleşim yerlerine, altyap1üstyapı tesislerine ve canlılara zarar vererek o bölgedeki ekonomik ve sosyal faaliyetleri kesintiye uğratan bir doğa olayıdır[16].

Taşkın olayı hem Dünyada hem de ülkemizde sıklıkla yaşanan olaylar arasında yer almakla beraber, taşkın afeti sonucunda çok ciddi can ve mal kayıpları yaşanmıştır. Uluslararası bir veri tabanına göre Dünyada son 100 yılda meydana gelen 2500 den fazla taşkın olayı sonucu 3 milyondan fazla insan hayatını kaybetmiş ve 200 milyar dolardan fazla maddi hasar meydana gelmiștir. Ülkemizde son 40 yılda yaşanan taşkın olayları sonucunda ise yüzlerce insanımız hayatını kaybetmiş, milyarlarca dolar zarar meydana gelmiştir [6]. Geçmiş yıllarda yaşanan taşkın olayları arasında 1995 yılı İzmir, 1996 yılı Trabzon-Beşköy, 1998 yılı Bartın, 2004 yılı Erzurum, 2006 yılı Batman, 2009 yılı İstanbul, 2012 yılı Samsun ve 2016 yılı Mersin taşkınları en çok zarara yol açan taşkınlar arasında yer almaktadır [2, 3, 4, 10 ve 13].

Sel ve taşkınlar; yağış şekli, yoğunluğu, drenaj ağ1 ve geometrisi, toprak özellikleri, bitki örtüsü gibi doğal birçok faktör ile şehirleşme, sanayileşme, ulaşım gibi beşeri kaynaklı faktörlerin etkisiyle oluşabilmekte ve yeterince önlem alınamadığı takdirde de afete dönüşebilmektedir [9].

Taşkın her ne kadar doğal bir afet olsa da, etkisinin bu derece büyük olmasının temel sebebi insan faaliyetleridir. İnsan faaliyetlerinin dışında, son yıllarda taşkınlardaki artışın bir diğer sebebi de iklim

\footnotetext{
${ }^{1}$ Sorumlu yazar: esraerturk@dsi.gov.tr Yazarların ORCID Numarası: ${ }^{1}$ 0000-0003-4395-6056, ${ }^{2}$ 0000-0002-9820-9587
} 
değişikliğidir. İklim değişikliğinden dolayı kısa sürelerde birim alana düşen yağış miktarındaki artış ani taşkınların yaşanmasına neden olmaktadır. Taşkın alanlarındaki yerleşimler, dere yataklarına yapılan müdahaleler, gelişen kentleşme ve sanayileşme faaliyetleri gibi insani etkenler nedeniyle akarsuların yüzey akışında olan artışlar, taşkın olayının yaşanmasına sebep olan diğer etkenlerdir. Bütün bu etkenler bir arada değerlendirildiğinde, taşkınların hem sayısında hem de meydana getireceği hasarlarda artış olacağı görülmektedir. Taşkın olayı, hem ulusal hem de yerel ölçekte gelişmeyi ve kalkınmayı etkileyen önemli bir faktör olduğu için taşkın olayının yaratacağı zararları minimize etmeyi amaçlayan taşkın yönetiminin önemi her geçen gün artmaktadır [8, 14].

Taşkın yönetimi, taşkını kontrol edebilmek, taşkının etkilerinin neler olacağını tespit edebilmek ve taşkının etkilerini ve zararlarını minimize etmek amacıyla yapılan tüm çalışmalardır. Taşkın yönetimi çalışmaları kapsamında taşkının muhtemel etkilerini göstermeye yönelik taşkın tehlike haritaları hazırlanmaktadır. Taşkın tehlike haritaları, mevcut taşkın sınırlarının haritalara işlenmesi, gelecek muhtemel taşkın tehlikesi taşıyan alanlar olarak kabul edilmesi, hidrolik ve hidrolojik modellere dayalı taşkın tehlike tahmini yapılması mantığına göre oluşturulmakta olup mevcut durum envanterinin ortaya koyulmasını sağlamaktadır [12, 14].

Potansiyel taşkın alanlarının belirlenmesinde, birçok yöntem ve yazılım mevcut olup, olasılık teorisi, istatistiksel yöntemler, Coğrafi Bilgi Sistemleri (CBS), CBS ile entegre programlar ve HEC-RAS, MIKE gibi programlar en çok tercih edilenler arasındadır [1]. Taşkın tehlike haritalarının olușturulmasında HEC-RAS, MIKE, SOBEK, FLO 2D, CBS vb. yazılımlardan yararlanılmakta olup, bu yazılımlar sayesinde tek boyutlu ve iki boyutlu taşkın modelleme çalışmaları oluşturulmaktadır. Geliştirilen bu hidrolik modeller ile elde edilmiş taşkın tehlike haritaları kullanılarak taşkınlar yaşanmadan risk altındaki alanlar tespit edilerek, bu doğrultuda olası zararları azaltıcı tedbirler alınmaya çalıșılmaktadır [5, 7]. Hidrolik modellemeler ile oluşturulan taşkın tehlike haritalarının faydaları ise aşă̆ıda verilmektedir:

- Dere boyunca veya belli bir noktada su seviyesinin yükselmesi durumunda erken uyarı yapılarak gerekli önlemlerin alınmasına zemin hazırlar.

- Taşkın kurtarma operasyonlarında afetten etkilenenlerin daha yüksek yerlere taşınması konusunda fayda sağlar.

- Yeni yerleșim yerlerinin planlanmasında ve olușturulmasında taşkın tehlike haritalarından faydalanılmaktadır.

- Taşkın Sigorta Sisteminde kullanılmak üzere sigorta şirketleri bu haritalara ihtiyaç duymaktadır [16].

Dünyada taşkın tehlikesinin yaşandığı ülkelerde (ABD, İngiltere, Hollanda, Fransa vb.) taşkın tehlike haritaları çalışmaları yürütülmekle beraber ülkemizde ise son 10 yıldan beri Su Yönetimi Genel Müdürlüğü, Devlet Su İşleri Genel Müdürlüğü ile ilgili belediyeler başta olmak üzere çeşitli kamu kurumlarınca bölgesel ve yerel taşkın tehlike haritaları hazırlanmaktadır [8]. Ülkemizde taşkın olayı yaşanması muhtemel yöreleri belirlemek ve taşkından oluşacak zararları azaltmak için taşkın tehlike haritalarının hazırlanmasından sonra taşkın risk haritalarına geçilmektedir [11]. Taşkın olayları genellikle Doğu Karadeniz Bölgesi, Orta Karadeniz Bölgesi dışında İstanbul, İzmir ve Mersin gibi büyük şehirlerimizde de şehir taşkınları olarak görülmektedir.

Çalışmanın amacı, HEC-RAS 1D ve 2D Boyutlu yazılımı kullanarak Doğu Karadeniz Havzasında yer alan akarsuların değişik taşkın tekerrür debilerinde $\left(\mathrm{Q}_{2}, \mathrm{Q}_{5}, \mathrm{Q}_{10}, \mathrm{Q}_{25}, \mathrm{Q}_{50}, \mathrm{Q}_{100}\right.$ ve $\left.\mathrm{Q}_{500}\right)$ su seviyelerini hesaplamak ve su altında kalacak yerleşim yerlerini ve tarım arazilerini belirlemektir. Bu çalışma kapsamında çalışma alanı olarak Trabzon-Vakfıkebir ilçesi Kirazlı deresi seçilmiştir. Çalışmada derenin taşkın hidrolojisi ve pürüzlülüğü ile ilgili daha önce yapılmış çalışmalardan yararlanılarak değişik debilerde HEC-RAS 1D ve 2D taşkın modellemeleri ile taşkın tehlike alanları belirlenmiştir. Çalışmanın sonuç kısmında debilere göre taşkının oluşma olasılığı ve etkilerinin neler olacağından bahsedilerek, taşkın yaşanmadan önce alınacak tedbirler ile ilgili öneriler sunulmuştur.

\section{Materyal ve Metot}

Taşkın olaylarının gündelik hayattaki zararlı etkileri günden güne daha da arttığından birçok Kurum/Kuruluş tarafından taşkın tehlike haritalarının oluşturulmasına daha çok önem verilmektedir. Bu kapsamda DSİ Genel Müdürlüğü başta olmak üzere diğer Kurum/Kuruluşların da taşkın tehlike haritalarının oluşturulmasına katkıları bulunmakla beraber Türkiye genelinde bu alanda yeterli sayıda çalı̧̧manın olmadığını da belirtmek gerekir.

Doğu Karadeniz Havzasında yer alan Kirazlı Deresinin potansiyel taşkın riski HEC-RAS 1 ve 2 boyutlu model ile değerlendirilerek alanında yapılan ilk çalışmalar arasında yer aldığı söylenebilir. Ayrıca bu çalışmada, bölgedeki taşkın riskini azaltmak için alınabilecek önlemlerden de bahsedilmiştir. Çalışma sonucunda tespit edilen 
sorunlara en uygun olabilecek çözümler önerilerek yapılan bu çalışmanın verimliliğini arttırmak ve özgünlüğünü sağlamak da hedeflenmiştir.

\subsection{Proje yerinin tanitılması}

Çalışma yeri olarak, taşkın olaylarının sıklıkla görüldüğü Doğu Karadeniz Bölgesi'nden bir yer seçilmiştir. Çalışma için seçilen yer, Doğu Karadeniz Bölgesi’ndeki Trabzon İli Vakfıkebir İlçesi'nde taşkın riski taşıyan Kirazlı Dere'dir. Proje yeri Şekil 1'de belirtilmektedir.

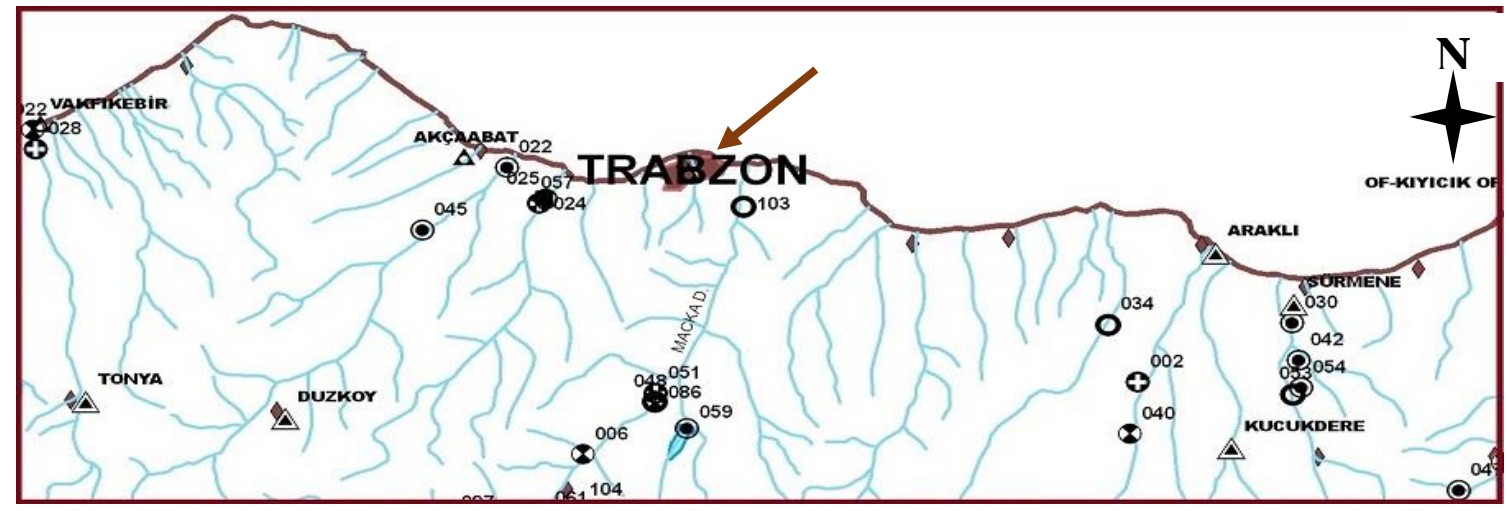

Şekil 1. Trabzon ili Vakfikebir ilçesi Kirazlı Deresi proje yeri.

Kirazlı Deresinin taşkın tehlike alanlarının ortaya koyulabilmesi için, 'Taşkın Hidrolojisi', 'Manning Pürüzlülük Katsayısı' ile '1 ve 2 Boyutlu HEC-RAS Modellemesi’ başlıkları altında yapılan çalışma anlatılmıştır.

\subsection{Taşkın hidrolojisi}

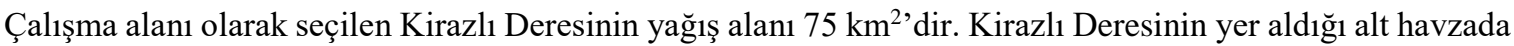
Meteoroloji İşleri Genel Müdürlüğü (MGI) tarafindan işletilen meteoroloji istasyonları ve Devlet Su İşleri (DSİ) Genel Müdürlüğü tarafindan işletilen Akım Gözlem İstasyonları (AGİ) bulunmadığı için, çevre havzada yer alan E22A028 (Fol Deresi) numaralı akım gözlem istasyonunun 1990-2013 yıllara arasındaki aylık ortalama akımlarından yararlanılarak hidrolojik çalışmalar yapılmıştır.

Söz konusu tablo incelendiğinde yıllar bazında Mart ve Nisan ayındaki akım değerlerinin en yüksek akım değerleri olduğu, Ağustos ayındaki akım değerlerinin ise en düşük akım değerleri olduğu gözlemlenmektedir.

Proje alanı olarak seçilen Kirazlı Deresinin yağış alanının $75 \mathrm{~km}^{2}$ olmasından dolayı DSİ Sentetik Yöntemi kullanılarak taşkın hesapları yapılmıştır. Yağış-Akış eğri $(\mathrm{CN})$ numarası 80 olan havzada proje alanı çevresindeki meteoroloji istasyonlarının yağış-süre-yinelenme (tekerrür) değerleri hesaplanarak gösterilmiştir. Kirazlı Deresine ait hidrolojik hesaplamalar yapıldıktan sonra, değişik taşkın tekerrür debilerinde $\left(\mathrm{Q}_{2}, \mathrm{Q}_{5}, \mathrm{Q}_{10}, \mathrm{Q}_{25}, \mathrm{Q}_{50}, \mathrm{Q}_{100}\right.$ ve $\mathrm{Q}_{500}$ ) pik debi değerleri bulunmuş ve oluşması muhtemel hidrograflar belirlenmiştir, bulunan pik debi değerleri ve belirlenen hidrograflar Şekil 2'de gösterilmiştir.

\subsection{Manning pürüzlülük katsayısı (n)}

Manning pürüzlülük katsayısını belirlemek için Devlet Su İşleri Genel Müdürlüğü tarafından 2016 yılında hazırlanan 'Dere Yatakları için Pürüzlülük Katsayısı Belirleme Kılavuzu’ndan yararlanılmıştır.

Kılavuz çerçevesinde pürüzlülük katsayısını belirlenmesi için yüzeyin pürüzlülüğü, bitki örtüsü, kanal düzensizliği, kanal eğriliği, birikim ve aşınma ve engeller gibi parametreler göz önünde bulundurulmuştur. Ayrıca söz konusu dere yatağında belirlenen değerler için laboratuvar ortamında elek analizi deneyleri yapılarak da pürüzlülük değerleri belirlenmeye çalışılmıştır. Parametrelerin göz önüne alınması sonucunda Kirazlı Deresi yatağ 1 için modelleme çalışmalarında kılavuzdan yararlanılarak pürüzlülük değeri 0.050 olarak alınmıştır. Ancak dere yatağı dışında yayılacak alanlarda engellerin (bina, yol vb.) ve daha pürüzlü olması sebebiyle 0.070 olarak alınmıştır [17]. 


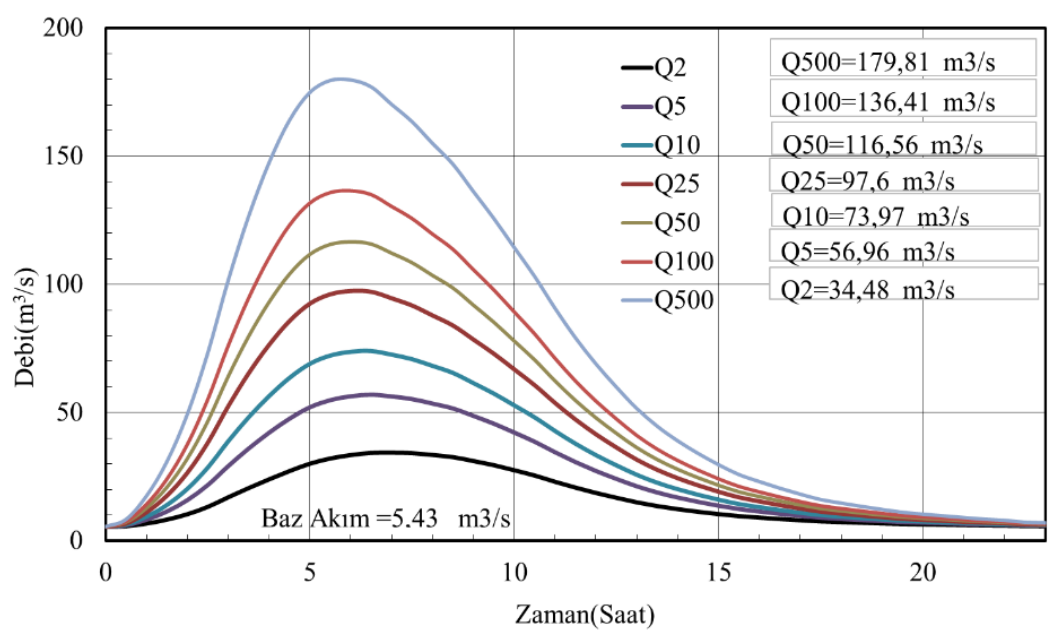

Şekil 2. Trabzon ili Vakfikebir ilçesi Kirazlı Deresi taşkın hidrograflar.

\subsection{1 ve 2 boyutlu HEC-RAS modellemesi}

Taşkın su derinliklerini ve tehlike haritalarını belirleme amacıyla kullanılan hidrodinamik modelleme çalışmalarında 1 boyutlu ve 2 boyutlu modeller ayrı ayrı veya entegre olarak çalıştırılabilmektedir. 1 boyutlu modellerin kullanımı genellikle, akış yönünün bilindiği kanallar veya basitçe bağlı (dendritik) kanal sistemleri ile sınırlıdır ve yerleşim yerlerindeki taşkınları modellemekte yetersiz kalabilmektedir. 2 boyutlu modelleme, üçgen, dörtgen veya beşgen olarak tanımlanabilen grid elemanlarında 2 boyutlu nümerik çözümlemesi ile yapılmakta olup yerleşim yerlerindeki taşkınları modelleyebilmektedir. 1 ve 2 boyutlu entegre modellerde ise ana kanal ve ana kanal üzerinde bulunan hidrolik yapılar (menfezler, köprüler, savaklar vb.) 1 boyutlu modelde tanımlanır ve 2 boyutlu modele dinamik olarak bağlanarak taşkın modellemesi gerçekleştirilir. 1 boyutlu modellerin yetersiz kaldığ 1 durumlarda 2 boyutlu modelin tek başına veya 1 ve 2 boyutlu modeller entegre bir şekilde kullanılmaktadır. HEC-RAS 1D boyutlu model ile köprü, menfez, yatak eğimleri, pürüzlülük katsayıları vb. veriler girilerek hidrolik yapıların tanımlanması yapılmakta ve yapılan modelleme çalışmalarına göre kesit boyunca su yüzü profilleri, su basma alanları, akım derinlikleri, akış hızları gibi taşkın karakteristikleri elde edilmektedir.

Proje kapsamında Coğrafi Bilgi Sistemleri (CBS) ile taşkın alanlarının belirlenmesi için ArcGIS, HECGeoRAS ve HEC-RAS 1D ve 2D programlarından yararlanılmıştır. ArcGIS uygulaması verileri görüntülemek, güncellemek, sorgulamak, analiz etmek ve verilere göre grafikleri oluşturmak için, HEC-GeoRAS sahaya ait geometrik veri katmanlarını oluşturmak için, HEC-RAS 1D ve 2D model sonuçlarından elde edilen su derinliklerini ve taşkın tehlike haritalarını belirlemek için kullanılmaktadır [18].

Çalışmanın yürütüldüğü ilk aşamada öncelikle Kirazlı Deresi için CBS ortamında elde edilen uydu görüntüsü Şekil 4'te sunulmuştur. Modellemenin yapılabilmesi için gerekli olan ve arazi yüzeyini en iyi temsil eden düzenli/düzensiz aralıklarla çok sayıda yükseklik ölçümünden oluşan 3 boyutlu sayısal yükseklik modeli (DEM) haritası ise Şekil 5'te sunulmuştur.

Kirazlı Deresi üzerinde yapılan modelleme çalışmalarında 3 adet köprü mevcut olup, köprülere ait açıklık, platform genişlikleri dikkate alınarak modelleme yapılmıştır. Köprülerle ilgili bilgiler Tablo 1'de verilmiştir.

Tablo 1. Köprülere ait bilgiler

\begin{tabular}{ccccc}
\hline \multirow{2}{*}{$\begin{array}{c}\text { Köprü } \\
\text { Numarası }\end{array}$} & $\mathbf{K m}$ & $\begin{array}{c}\text { Kiriş } \\
\text { Kotu } \\
(\mathbf{m})\end{array}$ & $\begin{array}{c}\text { Ayak } \\
\text { Açıklı̆̆ } \\
(\mathbf{m})\end{array}$ & $\begin{array}{c}\text { Kolon } \\
\text { Genişliği } \\
(\mathbf{m})\end{array}$ \\
\hline $\mathbf{1}$ & $0+030$ & 5,651 & $25-25$ & 1,5 \\
\hline $\mathbf{2}$ & $0+040$ & 5,593 & $25-25$ & 1,5 \\
\hline $\mathbf{3}$ & $0+080$ & 5,581 & $12-12$ & 1,2 \\
\hline
\end{tabular}




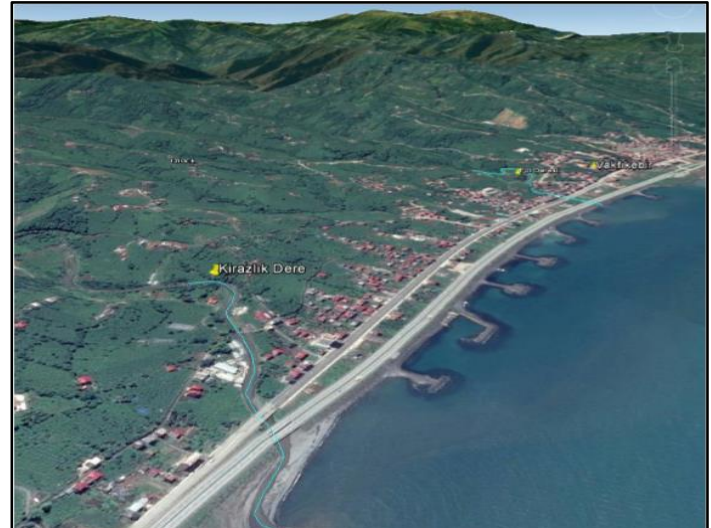

Şekil 3. Kirazlı deresi uydu görüntüsü

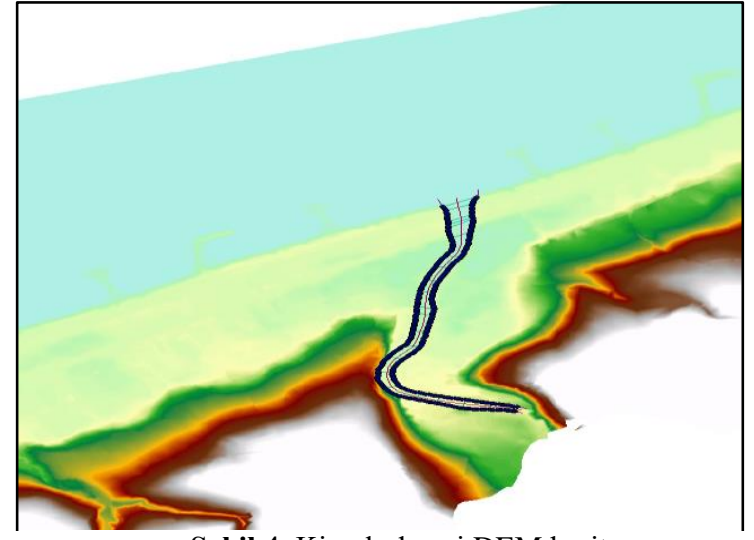

Şekil 4. Kirazlı deresi DEM haritası

Modellemeye başlamadan önce dere hattı, şev üstleri, akış yönü çizilmiş ve köprülerin durumları da göz önünde bulundurularak 50 metrede bir kesit atılmıştır. Kesit boyunca çalışan bir model olan HECRAS 1D modeli için öncelikle derede taşma olmaması ve taşma olması senaryolarına göre çalıştırılmış, derede taşma olayı olmaması durumundaki kesitin görünüşü Şekil 5'de, derede taşma olayı olması durumundaki kesitin görünüşü ise Şekil 6'da sunulmuştur.

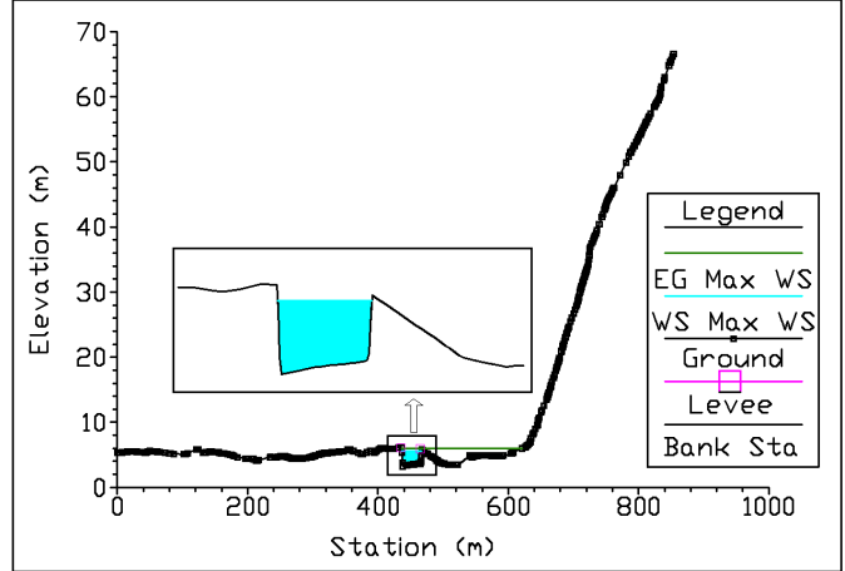

Şekil-5. HECRAS 1D modelde 0+393 km deki kesit

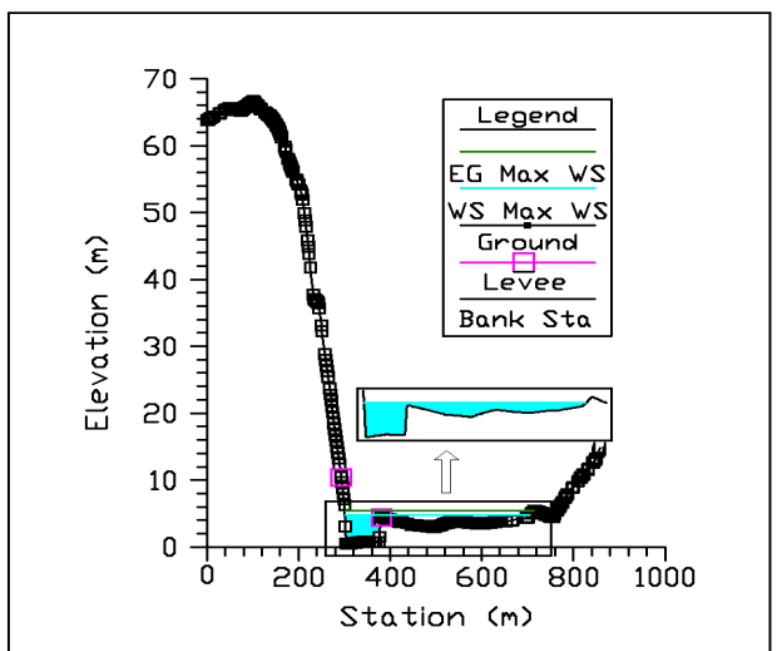

Şekil 6. HECRAS 1D modelde 0+650 km deki kesit 
Şekil 5 ve Şekil 6 incelendiği zaman, dere yatağından taşan suların nerelere yayılacağını belirleme konusunda HECRAS 2D modellemeye ihtiyaç duyulduğu anlaşılmaktadır. HECRAS 2D modellemesinde DEM verisine pürüzlülük ve köprü röleveleri işlenmiş, taşkın hidroloji bilgileri, denizin kabarma durumu da göz önünde bulundurularak deniz yükseltilmiş ve model çözdürülmüştür. HECRAS 2D modeline göre Kirazlı deresinin yatağı, kesit ve köprülerin görünümü Şekil 7'de sunulmuştur.

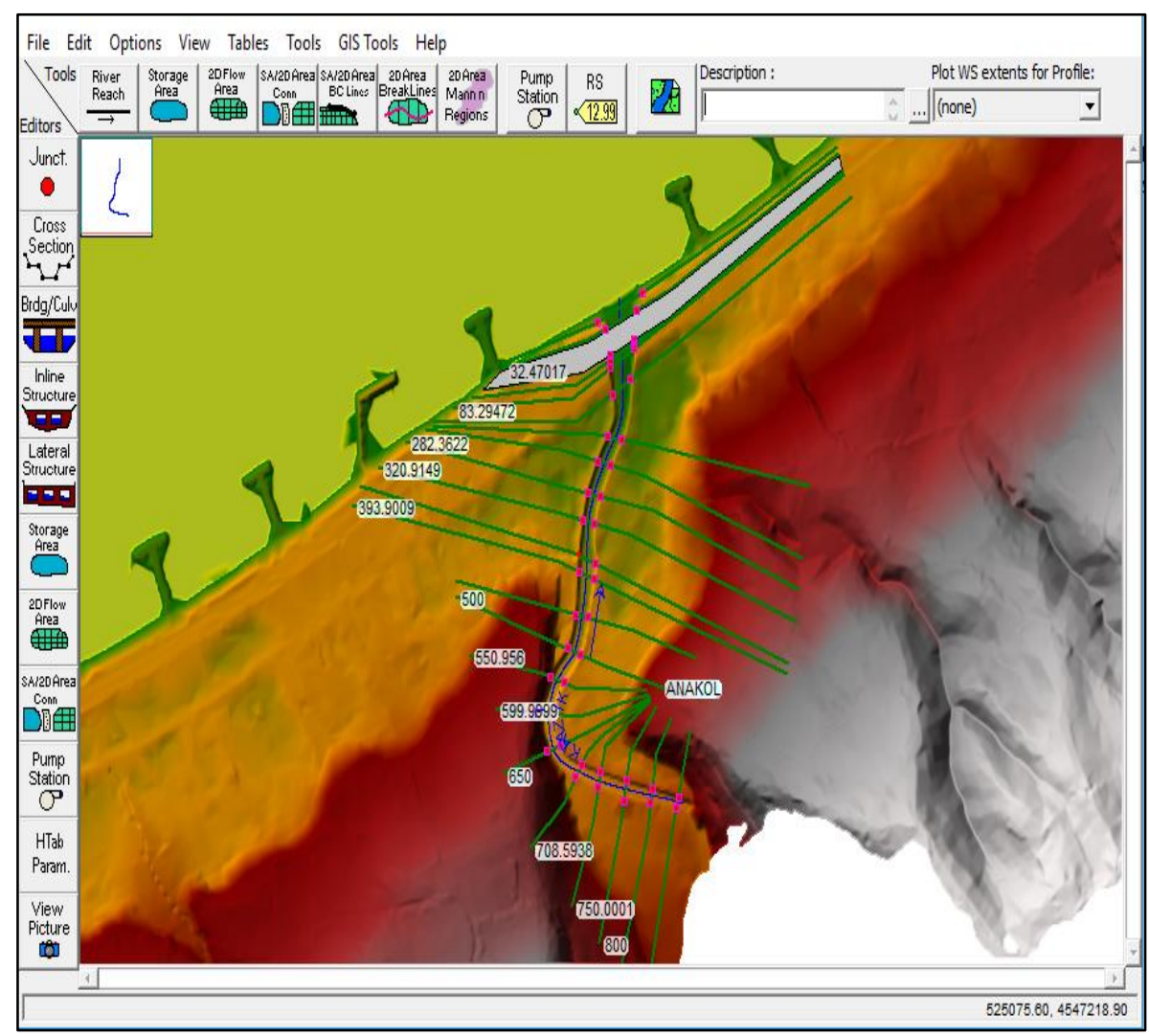

Şekil 7. HECRAS 2D modelde dere yatağ 1 , kesit ve köprüler

Şekil 7 incelendiği zaman, Kirazlı Deresi ile ilgili taşkın senaryoları 2 boyutlu modelde daha açık bir şekilde gözlemlenmektedir. Kirazlı Deresi üzerinde yapılan HEC-RAS 1D ve 2D modelleme sonuçlarından yararlanılarak $\mathrm{Q}_{500}$ taşkın debisine göre aşağıda yer alan formüller kullanarak taşkın hesaplamaları yapılmıştır. Yapılan bu hesaplamalar sonucunda taşkın derinlik haritası (Şekil 8), sonrasında derinlik haritasındaki v (hız) değerleri dikkate alınarak taşkın tehlike haritaları (Şekil 9) elde edilmiştir. Süprüntü Faktörü taşkının tehlike derecesini belirlemede bir etken olup, çalışmalarda kullanılan değerler Tablo 2'de verilmiştir [15].

Taşkın Tehlikesi (TT)=Derinlik x $\left(\mathrm{H}_{\mathrm{z}}+0,5\right)+$ Süprüntü faktörü

Taşkın Tehlikesi $(\mathrm{TT})=\mathrm{D} x(\mathrm{~V}+0,5)+\mathrm{SF}[15]$

Tablo 2. Süprüntü faktörü bilgileri.

\begin{tabular}{|c|c|c|c|}
\hline \multicolumn{4}{|c|}{ Süprüntü Faktörü } \\
\hline Derinlik \& Hız & $\begin{array}{c}\text { Otlak/Tarım } \\
\text { Arazisi }\end{array}$ & Orman & Şehir \\
\hline $0 \mathrm{~m}<$ Derinlik $<0,25 \mathrm{~m}$ & 0 & 0 & 0 \\
\hline $0,25 \mathrm{~m}<$ Derinlik $<0,75 \mathrm{~m}$ & 0 & 0,5 & 1 \\
\hline Derinlik $>0,75 \mathrm{~m}$ ve/veya $\mathrm{Hız}>2,00 \mathrm{~m} / \mathrm{s}$ & 0,5 & 1 & 1 \\
\hline
\end{tabular}


Şekil 8 ve 9 incelendiği zaman, $Q_{500}$ taşkın debisi kullanılarak yapılan modelleme sonuçlarına göre; Kirazlı dere yatağının $\mathrm{Q}_{500}$ taşkın debisini geçiremediği ve Kirazlı dere yatağının ilk olarak membada sol sahilden taşmakta olduğu, sonrasında ise dere yatağının kurp yaptığı bölgeden sağ sahilden taşmalar yaparak mansaba doğru yayıldığı, mansapta sol sahilde kalan bazı yerleşimlerin taşkına maruz kaldığı anlaşılmaktadır. Ek olarak, taşkın alanındaki su derinliğinin 2 metreye, dere yatağındaki derinliğin ise 4 metreye kadar ulaştı̆̆ anlaşılmaktadır.

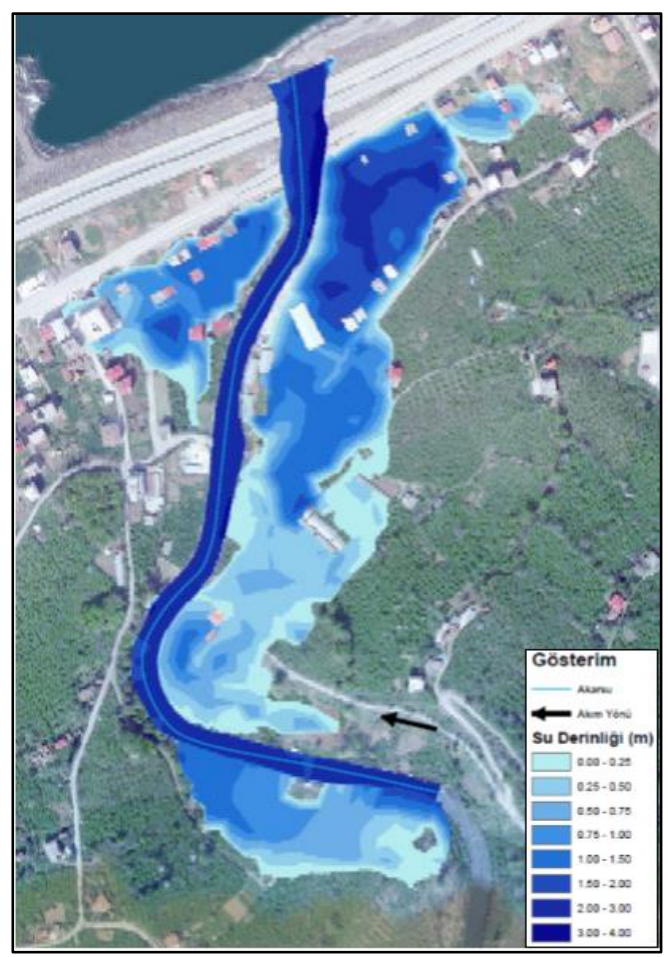

Şekil 8. HECRAS 2D modeli taşkın derinlik haritası

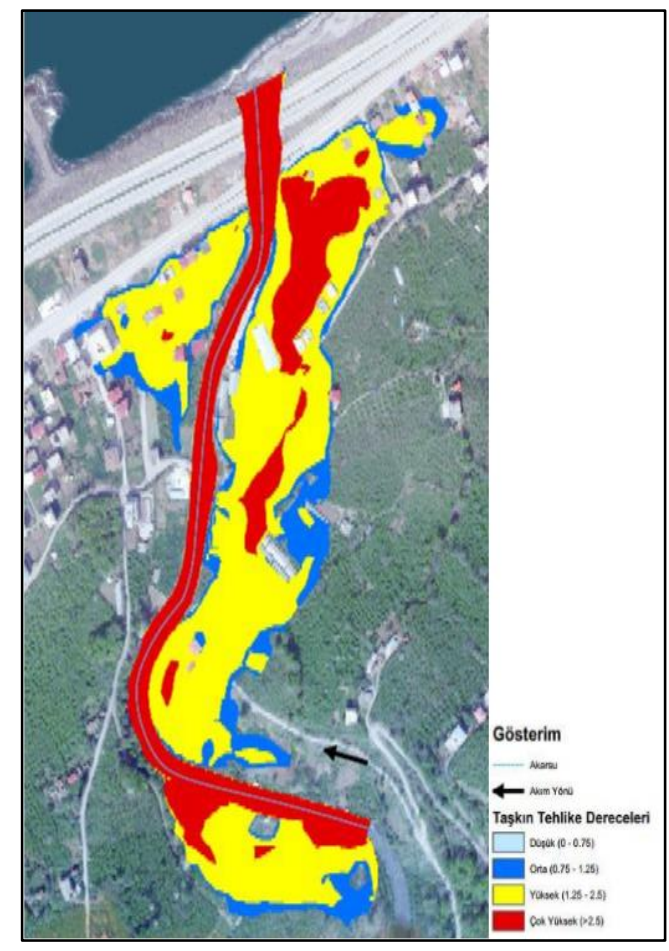

Şekil 9. HECRAS 2D modeli taşkın tehlike haritası

\section{Sonuçlar}

Aşırı yağış alan ve taşkın olaylarının sıklıkla yaşandığı bir bölge olan Doğu Karadeniz Bölgesi'nde taşkın olaylarının verdiği zararı minimize etmek için çeşitli taşkın kontrolü çalışmaları yapılmaktadır. Doğu Karadeniz Bölgesi'nde Trabzon ili Vakfikebir ilçesinde yer alan Kirazlı Deresi taşkın riski taşıyan dereler arasındadır. Bu çalışmalar arasında taşkın kontrolü tesislerinin inşa edilmesi gibi yapısal tedbirler ile taşkın tehlike haritalarının hazırlanması ve erken uyarı sistemlerinin kurulması gibi önleyici tedbirler yer almaktadır.

Kirazlı Deresi'nin yaratabileceği muhtemel taşkınların önüne geçmek için taşkın tehlike haritalarının hazırlanması amacıyla bu çalışma yapılmıştır. Çalışma sonucunda ortaya koyulan taşkın tehlike haritaları ile Kirazlı dere yatağının $Q_{500}$ taşkın debisini geçiremediği ve taşan suların sağ sahilden yaklaşık Km: 0+600 den başlayarak mansaptaki yerleşimlere kadar bölgeyi etkilediği gösterilmiştir.

Kirazlı dere yatağının taşması durumunda yaratacağı oluşabilecek zararları azaltmak amacıyla önerilen tedbirler Şekil 10'da sunulmuştur. Bu tedbirlerin en önde geleni, akarsu yatağında taşkının zarar verebileceği sağ sahilde Km: 0+150 ile Km: 0+650 arasındaki mevcut taşkın kontrol tesislerinin yükseltilmesidir, diğer tedbirler arasında ihtiyaca göre cam korkuluk, hareketli taşkın kontrol duvarları gibi yenilikçi tip yapısal tedbirler de önerilebilir.

Taşkın kontrol tesislerinin taşkının yaratabileceği zararları azaltacak şekilde yapılmasıı önemli olup, yapılan tesislerin yöre halkının rutin yaşamını zorlaştırmaması da önemlidir. Bu nedenle taşkın kontrolü tesislerinin yöre halkının dere yatağı ile irtibatı koparmayarak estetik bir şekilde inşa edilmesi uygun olacaktır. 


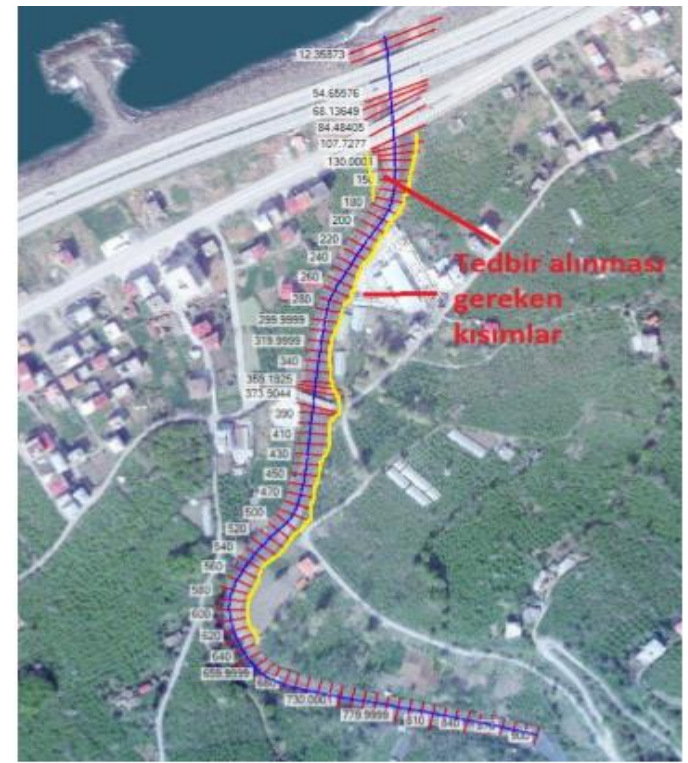

Şekil 10. Kirazlık deresi önerilen tedbirler

\section{Kaynaklar}

[1] Aksoy, H. ve arkadaşları (2004). Batı Karadeniz Bölgesi'nde potansiyel taşkın alanlarının belirlenmesine Yönelik Bir Çalışma. Türkiye Jeoloji Bülteni, 47 (2): 41-48.

[2] Avcı, S. 2000. Planlamadaki yanlışlıklar ve yol açtığı sorunlara bir örnek: 1998 selinde Filyos çayı havzasındaki etkileri ve sonuçları. 9. Ulusal Bölge Bilimi/Bölge Planlama Kongresi, (5-6 Ekim 2000). Trabzon.

[3] Bahadır, M. (2014). Samsun'da meydana gelen 4 Temmuz ve 6 Ağustos 2012 taşkınlarının klimatik analizi. Coğrafya Dergisi, 29: 28-50.

[4] Bilici, Ö.E. ve Everest, A. (2016). 29 Aralık 2016 Mersin selinin meteorolojik analizi ve iklim değişikliği bağlantısı. Doğu Coğrafya Dergisi, 38: 227-250

[5] Doğan, E. ve arkadaşları (2013). Aşağı Sakarya Nehrinde taşkın yayılım haritalarının elde edilmesi. SAÜ Fen Bilimleri Dergisi, 17(3): 363-369.

[6] Dölek, İ. (2013). Muş’ta yaşanan sel ve taşkınlara neden olan doğal faktörlerin analizi. Marmara Coğrafya Dergisi, 28: 408-422.

[7] Erdem, U. (2013). Yerleşimlerin taşıdığı deniz taşkını, sel ve deprem afet tehlikelerinin CBS kullanılarak yorumlanması: Balıkesir Örneği. BA ̈̈ Fen Bilimleri Enstitüsü Dergisi, 15(2): 40-57.

[8] Güngör, O. ve diğerleri (2016). Taşkın Tehlike Haritaları: Türkiye ve farklı Avrupa ülkelerinde yapılan çalışmaların karşı1ıklı olarak irdelenmesi. 4. Ulusal Taşkın Sempozyumu (23-25 Kasım 2016-Rize) Bildirileri, S. Korkmaz ve M. Akçay (Editörler), Ankara, 187-202.

[9] Karabulut, M. ve diğerleri (2007). 20 Kasım-9 Aralık Mersin sel felaketleri: Meteorolojik ve hidrolik açıdan bir inceleme. KSÜ Fen ve Mühendislik Dergisi, 10 (1): 13-23.

[10] Kömüşçü, A. ve diğerleri (2011). 8-12 Eylül 2009 Tarihlerinde Marmara Bölgesi’nde Meydana Gelen Sel Olayının Yağış Analizi, Coğrafi Bilimler Dergisi, 9 (2): 209-220.

[11] Özdemir, H. ve diğerleri (2013). Çokal Barajı (Çanakkale) çökme modeli ve taşkın risk analizi. Uluslararası İnsan Bilimleri Dergisi, 8: 659-698.

[12] Öztürk, D. ve diğerleri (2017). Çorum ili taşkın tehlikesinin analitik hiyerarşi yöntemi kullanılarak incelenmesi. TMMOB Harita ve Kadastro Mühendisleri Odası, 16. Türkiye Harita Bilimsel ve Teknik Kurultayı, 3-6 Mayıs 2017, Ankara Bildirileri.

[13] Sönmez, M. E. ve Kesici, Ö. (2010). İklim Değişikliği ve Plansız Şehirleşmenin Kilis Şehrinde Yol Açtığı Sel Felaketleri. Doğu Coğrafya Dergisi, 28: 58-78.

[14] Sunkar, M. ve Tonbul, S. (2010). Batman'da 31 Ekim-1 Kasım 2006 tarihinde yaşanan taşkının nedenleri. II. Ulusal Taşkın Sempozyumu 22-24 Mart 2010 Tebliğler Kitabı, Afyonkarahisar, 349-361.

[15] Turan, B. ve diğerleri (2016). Doğu Karadeniz Sahil Kesiminde Taşkın Etkisinin Taşkın Tehlike Haritaları ile Analizi. 4. Ulusal Taşkın Sempozyumu 23-25 Kasım 2016 Tebliğler Kitabı, Rize, 529-546.

[16] Orman ve Su İşleri Bakanlığı, Su Yönetimi Genel Müdürlüğü (2017). Taşkın Yönetimi, Ankara, 132-143.

[17] DSİ Genel Müdürlüğü, (2016). Dere Yatakları İçin Pürüzlülük Katsayısı Belirleme Kılavuzu, Ankara.

[18] DSİ Genel Müdürlüğü, (2013). Coğrafi Bilgi Sistemleri ile Taşkın Riski Ön Değerlendirmesi, Ankara. 